\title{
Weak association between HLA-DR4 and rheumatoid arthritis in Chilean patients
}

Loreto Massardo, Sergio Jacobelli, Luis Rodríguez, Santiago Rivero, Alfonso González, Rossana Marchetti

\begin{abstract}
Evidence has suggested a genetic link between the HLA-DR4 phenotype and rheumatoid arthritis (RA), particularly in its seropositive form. Such an association varies among different ethnic groups and remains controversial for seronegative patients. Data obtained for a group of 64 Chilean patients with RA (46 seropositive, 18 seronegative), as defined by the 1987 criteria of the American Rheumatism Association, and for 76 controls are reported here.

The prevalence of HLA-DR4 and DR9 was significantly increased in the group of patients considered as a whole. The prevalence of HLA-DR4 was not significantly higher, however, when seronegative and seropositive patients were separately compared with controls. Also, it did not correlate with the severity of the disease within each subgroup of patients. On the other hand, HLA-DR9 showed a highly significant difference, not previously described, only for the seropositive patients in comparison with controls. The prevalence of DQ specificities showed no relevant differences among the groups.

The HLA-DR4 serotype, therefore, is a weak marker for RA and does not differentiate any subgroup of patients in the Chilean group studied. This new finding, indicating an association between RA and the DR9 antigen, may be explained by the suggestion that susceptibility epitopes are shared among different DR molecules. This hypothesis might also account for the variation in the association of DR4 with RA.
\end{abstract}

Pontificia Universidad Católica de Chile, School of Medicine, Department of Clinical Immunology and Rheumatology, and Hospital Sótero del Río

L Massardo

S Jacobelli

L Rodríguez

$S$ Rivero

A González

R Marchetti

Correspondence to: Dr Sergio Jacobelli, Pontificia Universidad Católica de Chile,

School of Medicine

Department of Clinica

Immunology and

Rheumatology,

Rheumatology,

Santiago, Chile.

Accepted for publication

10 July 1989
Although there is now sufficient evidence to indicate that development of rheumatoid arthritis (RA) is genetically linked to the class II region of the major histocompatibility complex ${ }^{1}$ identification of the involved genes has proved elusive. Most reports have pointed to a significant association with the HLA-DR4 antigen. Because of the variability of the HLA polymorphism distribution among different populations, however, the prevalence of this antigen in patients with RA cannot be extrapolated throughout the world. This limitation is clearly shown by the fact that the reported prevalence of the DR4 antigen is between 50 and $80 \%$ in patients with RA and between 15 and $35 \%$ in controls. ${ }^{2-7}$ In some cases a better association has been found with the DR1 antigen ${ }^{49}$ or with both DR4 and DR1 antigens. ${ }^{10}$ In addition, other authors have reported no association at all between RA and HLA-DR antigens in their respective populations. ${ }^{11} 12$ The association of DR4 and RA is more obvious with seropositive disease, ${ }^{3513}$ however, though remains controversial for seronegative RA. ${ }^{73-15}$ Finally, other antigens may contribute, together with those defining DR specificities, to the risk of acquiring the disease. For instance, HLA-DR4 is in linkage disequilibrium with the DRw53 and DQw3 antigens, forming a haplotype. ${ }^{16}$ These antigens predict similar relative risks for $\mathrm{RA}$ as the subtype DR4. ${ }^{317-19}$

All these considerations prompted us to analyse the prevalence of HLA-DR and DQ antigens in our own population of patients with seropositive and seronegative RA as a first step towards obtaining relevant information to direct our research on the genetic factors involved in the susceptibility to RA in Chilean patients.

\section{Patients and methods}

Sixty four unrelated patients with RA, classified according to the 1987 revised American Rheumatism Association criteria, ${ }^{20}$ were compared with 76 healthy controls, all living in the metropolitan area of Santiago, Chile. Forty six patients had seropositive RA (42 women, four men), with an average age of 47 years and an average disease duration of 8.5 years; all had been treated with gold salts, penicillamine, or immunosuppressive agents. Thirty nine (85\%) of these patients had erosive disease. The remaining 18 patients had seronegative RA (16 women, two men), with an average age of $43 \cdot 1$ years and an average disease duration of 5.5 years. Seven $(39 \%)$ of these patients had erosive disease and seven had received gold salts. Patients classified as seronegative had had at least four negative determinations of the latex agglutination test (normal up to $1 / 40$ ), one of which had been carried out before their use of long acting remission drugs. HLA-B27 was negative in the 13 seronegative patients tested.

The 76 normal controls were laboratory personnel and organ donors. HLA determinations were made with the microcytotoxicity test described by Terasaki et $a l .^{21}$ Antisera were purchased from One Lambda (Los Angeles California, USA). The samples were processed in the histocompatibility laboratory at the university hospital. HLA-DR1 to DRw10, DRw52, DRw53, and DQw1 to DQw3 were determined in all patients. DRw52, DRw53, and DQ were determined in 66 of the controls. Prevalences were compared by the $\chi^{2}$ test and a relative risk (RR) (odds ratio) was calculated. ${ }^{22}$ 
Results

Table 1 shows the prevalence of the HLA-DR antigens found in patients with $R A$ and in controls. Both DR4 and DR9 serotypes showed significant differences compared with the control group. For DR4 this difference was significant only when all the patients with RA were compared with the controls $(p=0.042)$. When the patients were separated according to the presence of rheumatoid factor the significance was lost $(p=0.118$ for the seropositive and $p=0.0571$ for the seronegative patients). Analysis of the DR4 association with seropositive RA gave an $R R$ of 1.8 while for the seronegative group it was $2 \cdot 7$. On the other hand, even though the number of patients with DR9 was small, this serotype showed a highly significant difference between seropositive patients and controls ( $p=0.002, R R=6.76)$; six out of the 10 DR9 positive patients were also DR4 positive and none of the seronegative patients had the DR9 phenotype.

Serotype DR1 was increased in the patients, without reaching statistical significance. The prevalence of this antigen in the DR4 negative patients was $32 \%$ in the seropositive group and $50 \%$ in the seronegative group, compared with $19 \%$ of the DR4 negative controls (data not shown). These differences were not significant.

Table 2 shows that the prevalences of DRw52, DRw53, and DQ antigens were not significantly different among the groups. Nineteen of the 21 DR4 positive, seropositive patients had the haplotype DR4-DRw53-DQw3 compared with seven of the 10 seronegative patients and 17 of 24 controls.

\section{Discussion}

A genetic basis for RA susceptibility is indicated by a higher than normal incidence of this

Table 1: Prevalence of HLA-DR antigens in patients with rheumatoid arthritis $(R A)$ and in controls. The number of patients is given with the percentage in parentheses

\begin{tabular}{|c|c|c|c|c|}
\hline \multirow{2}{*}{$\begin{array}{l}\text { HLA } \\
\text { antigens }\end{array}$} & \multicolumn{3}{|c|}{ Rheromatoid arthritis } & \multirow{2}{*}{$\begin{array}{l}\text { Controls } \\
(n=76)\end{array}$} \\
\hline & $\begin{array}{l}A l l R A \\
(n=64)\end{array}$ & $\begin{array}{l}\text { Seropositive } \\
(n=46)\end{array}$ & $\begin{array}{l}\text { Seronegative } \\
(n=18)\end{array}$ & \\
\hline $\begin{array}{l}\text { DR1 } \\
\text { DR2 } \\
\text { DR3 } \\
\text { DR4 } \\
\text { DR5 } \\
\text { DRw6 } \\
\text { DR7 } \\
\text { DRw8 } \\
\text { DR9 } \\
\text { DRw10 }\end{array}$ & $\begin{array}{r}17(27) \\
15(23) \\
7(11) \\
31(48) \\
6(9) \\
6(9) \\
7(11) \\
10(16) \\
10(16) \\
0\end{array}$ & $\begin{array}{r}11(24) \\
10(22) \\
7(15) \\
21(46) \\
4(9) \\
4(9) \\
5(11) \\
6(13) \\
10(22) \\
0\end{array}$ & $\begin{array}{l}6(33) \\
5(28) \\
0 \\
10(56) \\
2(11) \\
2(11) \\
2(11) \\
4(22) \\
0 \\
0\end{array}$ & $\begin{array}{l}12(16) \\
23(30) \\
20(26) \\
24(32)^{*} \\
15(20) \\
11(14) \\
16(21) \\
7(9) \\
3(4) \dagger \\
4(5)\end{array}$ \\
\hline
\end{tabular}

Significant $\chi^{2}$ comparisons:

DR4: All RA comparisons: $p=0.042, R R=2.04$

tDR9: All $R A v$ controls: $p=0.017, R R=4.51$.

Table 2: Prevalence of HLA-DRw52, DRw53, and DQw antigens in patients with rheumatoid arthritis and in controls. The number of patients is given with the percentage in parentheses

\begin{tabular}{lllll}
\hline $\begin{array}{l}\text { HLA } \\
\text { antigens }\end{array}$ & \multicolumn{2}{l}{ Rheumatoid arthritis } & $\begin{array}{l}\text { Controls } \\
(n=66)\end{array}$ \\
\cline { 2 - 5 } & $\begin{array}{l}\text { All RA } \\
(n=64)\end{array}$ & $\begin{array}{l}\text { Seropositive } \\
(n=46)\end{array}$ & $\begin{array}{l}\text { Seronegative } \\
(n=18)\end{array}$ & \\
\hline DRw52 & $28(44)$ & $21(46)$ & $7(39)$ & $49(74)$ \\
DRw53 & $34(53)$ & $25(54)$ & $9(50)$ & $38(58)$ \\
DQw1 & $32(50)$ & $24(52)$ & $8(44)$ & $34(52)$ \\
DQw2 & $13(20)$ & $11(24)$ & $2(11)$ & $13(20)$ \\
DQw3 & $46(72)$ & $33(72)$ & $13(72)$ & $44(67)$ \\
\hline
\end{tabular}

disease in monozygotic twins ${ }^{23}$ and by an association with the HLA-DR4 serotype, seen especially in seropositive RA..$^{2-5}{ }^{13}$ Studies made on different populations have shown that DR4 association with RA is not equally distributed throughout the world. ${ }^{124}$ Our results strengthen this suggestion, thus emphasising the limitation of the DR4 phenotype as a marker for RA susceptibility.

Although our group of patients had a significant increase in the prevalence of DR4 compared with controls, this significance disappeared when seropositive and seronegative patients were compared as separate groups with the controls. Even though the RR for both groups was 1.8 and 2.7 respectively, and therefore a positive association cannot be excluded, our figures are lower than those found in studies where a positive association is described. ${ }^{2-5} 13$ Thus it seems clear that the DR4 phenotype association with our seropositive patients is weaker than in most other reported studies.

Because the presence of rheumatoid factor is associated with more severe disease ${ }^{25}$ it has been suggested that HLA-DR4 might be a marker for the severity of the arthritis. ${ }^{326} 27$ It could be argued then that our seropositive patients had a mild disease, which would explain their lower prevalence of DR4. We do not consider this argument applicable to our population because most of our patients had erosive disease and, in addition, our seronegative patients had overall milder disease but their association with DR4 was stronger $(R R=2 \cdot 7)$. Furthermore, DR4 could not identify a definite subset of patients in this group, and erosive disease was equally distributed among DR4 positive and negative patients.

The validity of the DR4 serotype as a susceptibility marker for seronegative RA remains controversial. ${ }^{14}$ Some authors have instead reported a significant increase in DR1 for this subgroup of patients. ${ }^{13}$ The reported differences in the prevalence of DR4 in seronegative patients may be due in part to the different criteria used in defining this form of RA. Thus we used the recent criteria of the American Rheumatism Association and these excluded many subjects that otherwise, according to former criteria, might have been classified within this group.

The DR1 prevalence was also increased in our patients, though this did not reach statistical significance. Also, a non-significant difference in the distribution of DRw53 and DQw3 antigens was found. This might be expected as both antigens are linked to DR4, ${ }^{28}$ and a recent study shows that neither of them was increased in patients with RA who did not have DR4. ${ }^{14}$

A striking finding, not previously described, was the significantly greater prevalence of DR9 found in our seropositive patients. Determination of the relevance of this serotype as a marker for RA in our population requires a study of a larger number of patients. As discussed below it may be that the DR9 antigen of our patients shares with DR4 and DR1 antigens some common functionally important molecular feature. Although it is widely accepted that HLA class II (D region) antigens play a 
crucial part in the pathogenesis of RA, the relation between structure and function of these antigens and the susceptibility for RA remains to be determined. The clear association with DR4 shown in several studies points to the DR $\beta 1$ chain as one of the molecular elements primarily involved. The reports of the weakness of this association found in some ethnic groups and in different populations, ${ }^{1}$ including our own, suggest that some information about the DR 11 structure, not recognised by DR4 alloantisera, is being lost. ${ }^{24} \mathrm{~A}$ source of complexity lies in the fact that not all the DR4 antigens are the same, but there are subspecificities defined by very small differences in a discrete regionnamely, the hypervariable III region of the $\beta$ chain. ${ }^{29}$ These subtypes are not equally associated with RA and, moreover, identical hypervariable III regions may be found in different DR antigens. The DR4 alleles bearing the specific sequences of this region corresponding to Dw4 or Dw14 subtypes have been associated with RA. ${ }^{28}{ }^{29}$ When the association of RA with the DRl antigen found in some ethnic groups and in some DR4 negative patients with RA is considered $^{14}$ it is interesting to note that the sequence of the third hypervariable region of the DR4, Dw14 subtype is identical with the corresponding region on some DR1 alleles found in patients with RA. ${ }^{28} 29$

The possibility that other DR alleles might contain, in discrete regions of their structure, epitopes important in conferring RA susceptibility has also been suggested by the fact that the 109-d6 monoclonal antibody, a stronger marker than DR4 for the disease, recognises an epitope which is shared by DR4, DR1, and DR9 alleles, presumably located in their third hypervariable region. ${ }^{18}$ Such an epitope, therefore, might contribute to RA susceptibility even when present in DR alleles other than DR4, and might well be related to the fact that we found a significant association between DR9 and RA, with an $R R$ of 4.5 , which is stronger than the RR of 2.04 for DR4. When only seropositive patients are considered the RR for DR9 is even stronger $(R R=6 \cdot 76)$.

If these regions are the really important structures functionally related to susceptibility to $\mathrm{RA}$, then the prevalence of their representation in distinct $D R$ antigens would influence the strength of the association with a particular DR haplotype in a given population. We do not know whether the DR4 subtypes of our patients are the same as those of the DR4 positive controls. An attempt is now being made, using specific DNA probes, ${ }^{29}$ to determine this. We suggest that our DR9 patients may share at the third hypervariable region certain sequences of Dw4 or Dw14 subtypes.

All the above mentioned considerations show that several factors may have unpredictable relative contributions to DR4 associations with $\mathrm{RA}$ and point to the need to search for the genetic structure of RA in a more multifactorial way, including genomic analysis using cDNA probes, rather than through the common approach of assessing only DR prevalences through alloreactivity. We have taken this into account and studies are now in progress to characterise further our population of patients with RA.

We would like to thank Dr Michael Lockshin and Dr Paul Dieppe for their helpful review of the manuscript and Miss Edith Mira for her secretarial expertise. Supported in part by a Mira for her secretarial
Fondecyt grant No 717/87.

1 Jeannet $M$. Class II antigens in autoimmune and immunomediated diseases. In: Solheim B G, Moller E, Ferrone S, eds. HLA class II antigens: a comprehensive review of structure and function. Berlin: Springer 1986: 489-514.

2 Stast $P$ Association of the B-cell alloantigen DRw4 with rheumatoid arthritis. $N$ Engl $f$ Med 1978; 298: 869-71

3 Jaraquemada D, Ollier W, Awad J, et al. HLA and rheumatoid arthritis: a combined analysis of 440 British patients. Ann Rheum Dis 1986; 45: 627-36.

4 Woodrow J C, Nichol F C, Zaphiropoulos G. DR antigens and rheumatoid arthritis: a study of two populations. $\mathrm{Br}$ Med F 1981; 283: 1287-8.

5 Alarcón G, Koopman W, Acton R, Barger B. Seronegative rheumatoid arthritis: A distinct immunogenetic disease? Arthritis Rheum 1982; 25: 502-7.

6 Panayi G S, Wooley P, Batchelor J R. Genetic basis of rheumatoid arthritis: HLA antigens, disease manifestations and toxic reactions to drugs. Br Med F 1978; ii: 1326-8.

7 Panayi G S, Wooley P H, Batchelor J R. HLA-DRw4 and rheumatoid arthritis. Lancet 1979; i: 730 .

8 Ferraccioli G, Savi M. Association between DR antigens, rheumatoid arthritis with and without extraarticular feature and systemic lupus erythematosus in northern Italy f Rheumatol 1988; 15: 51-3.

9 Schiff B, Mizrachi S, Orgard M, et al. Association of HLAAw31 and HLA-DR1 with adult rheumatoid arthritis. Ann Rheum Dis 1982; 41: 403-4.

10 Nuñez A, Arquer E, Villechenous E, De La Prada M Estudio de los antígenos HLA-DR en Artritis Reumatoídea. Revista Espanola de Reumatologia 1982; 9: 9-11.

11 Papasteriades C A, Kappou I D, Skopouli F N, et al. Lack of HLA-antigen association in Greek rheumatoid arthritis patients. Rheumatol Int 1985; 5: 281-3.

12 Wilkens R F, Hansen J A, Malmgren J A, et al. HLA antigens in Yakima indians with rheumatoid arthritis: lack of association with HLA

13 Bardin T, Legrand L, Naveau B, et al. HLA antigens and seronegative rheumatoid arthritis. Ann Rheum Dis 1985; 44 $50-3$.

14 Masi A. Rheumatoid factor negative(seronegative) rheumatoid arthritis: evolving clinical classification and immunogenetic association. $\mathcal{F}$ Rheumatol 1988; 15: 4-6.

15 Tore J T, Husby G, Thorsby $\mathrm{E}$. The association between rheumatoid arthritis and the HLA antigen DR4. Ann Rheum Dis 1983; 42: 292-6.

16 McCusker C T, Singal D P. Molecular relationships between the class II HIA antigens and susceptibility to rheumatoid arthritis. F Rheumatol 1988; 15: 1050-3.

17 Duquesnoy R, Marrari M, Hackbarth S, Zeevi A. Sero logical and cellular definition of a new HLA-DR associated determinant, $\mathrm{MCl}$ and its association with rheumatoid arthritis. Hum Immunol 1984; 10: 165-76.

18 Lee S H, Matsuyama T, Logalbo P, et al. Ia antigens and susceptibility to rheumatoid arthritis. Clin Rheum Dis 1985 11: 645-64.

19 Singal D, D'Souza M, Reid B, et al. HLA-DQ beta-chain polyporphism in HLA-DR4 haplotypes associated with rolyporphism in Hitoid arthritis. Lancet 1987; ii: 1118-20.

20 Arnett F A, Edworthy S M, Bloch D A, et al. The American Rheumatism Association 1987 revised criteria for the Rheumatism Association 1987 revised criteria for the
classification of rheumatoid arthritis. Arthritis Rheum 1988; 31: 315-24.

21 Terasaki P, McClelland J D, Park M S, McCurdy B. Microdroplet lymphocyte cytotoxicity test. In: Manual of tissue typing techniques. Washington DC: DHEW Publisher (NIH) US Government Printing Office, 1973: 73-545.

22 Blandt-Johnson R C, Johnson N L. Survival models and dat analysis. In: Bradley $R$ A, Hunter J S, Kendall D G Watson G S, eds. Probability and mathematical statistics. New York: Wiley, 1980: 34-8.

23 Aho A Koskenvuo M, Tuominen J, Kaprio J. Occurrence of rheumatoid arthritis in a nationwide series of twins. rheumatoid arthritis in a natio

24 Woodrow J C. Immunogenetics of rheumatoid arthritis. f Rheumatol 1988; 15: 1-3.

25 Mongan E S, Atwater E C. A comparison of patients with seropositive and seronegative rheumatoid arthritis. Med seropositive and seronegative
Clin North Am 1968; 52: 533-8.

26 Olsen N J, Callahan L F, Brooks R H, et al. Associations of HLA-DR4 with rheumatoid factor and radiographic severity in rheumatoid arthritis. Am $\mathcal{F}$ Med 1988; 84: 257-64.

27 Young A, Jaraquemada D, Awad J, et al. Association of HLA-DR4/Dw4 and DR2/Dw2 with radiologic changes in prospective study of patients with rheumatoid arthritis. Preferential relationship with HLA-Dw rather than HLADR specificities. Arthritis Rheum 1984; 27: 20-5.

28 Gregersen P K, Silver J, Winchester R J. The shared epitope hypothesis: an approach to understanding the molecular genetics of susceptibility to rheumatoid arthritis. Arthritis Renetics of susceptibility 1987 ; 30: 1205-13.

29 Nepom G T, Byers P, Seyfried L A, et al. HLA genes associated with rheumatoid arthritis identification of susceptibility alleles using specific oligonucleotide probes. ceptibility alleles using specif
Arthritis Rhewm 1989; 32: 15-21. 